\title{
Effects of Forest Plant Healing Therapy on School Stress and Affectivity in College Students
}

\author{
Eun-Jin Lee ${ }^{1}$ and Chang-Duck Koo ${ }^{2}$ * \\ ${ }^{1}$ Graduate Department of Forest Therapy, Chungbuk National University, Cheongju 28644, Korea \\ ${ }^{2}$ Department of Forestry, Chungbuk National University, Cheongju 28644, Korea
}

\begin{abstract}
This study was conducted to find out the effect of pre- and post-plant therapy, which is one of six major forest healing methods, on male and female college students' positive and negative affect and stress in college life. The healing program reflecting on students' past, present, and future was conducted at Chungbuk National University Woraksan Research Forest in late March for 1st, 2nd, and 3rd year students attending the department of forestry at Chungbuk National University. A questionnaire regarding school stress and affect states was surveyed before and after the healing program which lasted two and half hours. The collected data were used to test and analyze the effect of pre-and post-plant therapy utilizing a paired t-test. The study found that after plant therapy there was not a significant change in average stress scores of the participants $(p=.06)$. However, there was a significant increase in the average score for postivie emotions $(p=.000)$ and decrease for negative emotions $(p=.000)$ Gender differences in afffective responses reported male students showed greater changes in positive and negative affect than did female students. The results show that plant therapy had a positive effect on college students' emotions. It also suggests plant therapy has potential applications in maintaining the emotional stability of college students. However, as the short-term effects for the short period of time have been verified, further studies are needed.
\end{abstract}

Keywords: five senses, forest, healing, PANAS (Positive Affect and Negative Affect Schedule)

\section{Introduction}

Stress is prevalent among all social classes today, but stress of college students is especially more serious (Hwang, 2012). College students have multidimensional developmental tasks of having to form secure identity and adapt to a new environment of individual freedom and social relationship building. They are also expected to perform independent and active roles at home or in society while they are still mentally controlled and dependent without completely being free from the state of high school students. In addition to these developmental tasks, they also face changes into a new environment of college, thereby suffering great stress (Shin, 2014). According to Selye (1982), stress threatens the well-being of individuals by causing maladjustment to life that lasts from birth to death, and also causes diseases. People have various ways to deal with psychological problems like stress, one of which is encountering nature. The forest environment is known to be a place to promote mental and physical health as it is scientifically reported to have specific 
substances from trees as well as various other elements. Moreover, the healing effect of forests on protecting health is obtained not just by enjoying a natural landscape but also by being in nature. Being in nature provides benefits of stable emotional state such as pleasant stimulation and tension relaxation, helps in harmonious restoration of the overall brain functions (Lee, 2015), and provides us with health, creativity and happiness.

$\mathrm{Yu}$ (2007) stated that physical and environmental elements such as phytoncide, landscape, sound, anion, temperature and humidity, light, and topography of forests all provide effects along with healing programs, and Kim et al. (2008) classified therapy that can be applied to healing activities in the forest with focus on environmental elements as well as social and psychological factors into six types of healing therapy: plant therapy, water therapy, climate therapy, psychotherapy, diet therapy, and kinesiotherapy (Kim et al., 2011). Li and Kawada (2013) discovered that phytoncide promotes natural killer cell activities that reinforce human immunity, increases anti-cancer proteins, and reduces stress, while also suggesting that constantly visiting forests are effective in preventing occurrence and spread of cancer (Kusuhara et al., 2012).

Plant therapy is a health remedy using plants within the forest (Oh et al., 2016) and it includes forest therapy, forest climate therapy, anion therapy and aromatic bath. There are also pressed flowers, grass leaf crafts, plant observations, wild grass experience and forestry operation experience (Korea Forest Service, 2011), but plant therapy used in this study is mainly on observation, with focus on the following of the five senses: sense of sight looking at winter buds and flowers through bitter cold and fresh sprouts and flowers shooting out of the frozen ground using a loupe or observing the growth of a tree from the ground surface to the tip of the branches, sense of smell sniffing the scents of flowers and leaves that bloomed in early spring, and sense of touch feeling bark, fallen leaves and fruits.

Studies on college students are mostly about employment stress, anxiety, frustrated desire for interpersonal relations (Choi, 2013), and aggression and suicidal ideation. However, there are insufficient studies on contents about college students' adjustment to school life or whether plant-based healing helps provide emotional stability. Therefore, this study determines the positive effects of plant therapy on school adjustment, stress relief, stability of positive emotions and reduction of negative emotions in terms of school life stress of college students, and also examines the differences between male and female students.

\section{Research Methods}

\section{Subjects and methods}

This study used the outdoor learning of total 82 students in the Department of Forest Science at Chungbuk National University at the end of March, consisting of 30 students in the first year, 27 in the second year, and 25 in the third year. The procedures of the experiment are as follows. Students filled out the self-report questionnaires of school life stress and the Positive Affect and Negative Affect Schedule (PANAS) before participating in outdoor learning at the university located in Cheongju. They then moved to Woraksan Mountain to experience the plant therapy program among the six forest healing therapies, and filled out the posttest survey after that. The program was implemented by dividing the students into four groups with all three years mixed together, and each group carried out individual activities led by the guide.

\section{Study area}

The place for the forest healing program was the research forest affiliated with Chungbuk National University located in Woraksan Mountain, Songgye-ri, Hansu-myeon, Jecheon-si, Chungbuk. The forest is in the eastern direction and has an 
altitude of 400-500m and a slope of 30 35 ${ }^{\circ}$. Around it is a mixed forest of soft and hardwood, mostly pine. The diameter at breast height is at least $30 \mathrm{~cm}$ and the age is at least 51-60 years, and the crown density is at least $71 \%$. In addition, other oak has the diameter of $18-30 \mathrm{~cm}$ and age of 31-40 years. The data of Korea Forestry Promotion Institute is renewed every 5 years (Korea Forestry Promotion Institute (KOFPI), 2018).

The annual mean temperature of the study area is $11-12^{\circ} \mathrm{C}$ and the precipitation is $1200-1300 \mathrm{~mm}$ (Korea Meteorological Administration, 2018b). The highest temperature in March was 19 20 ${ }^{\circ} \mathrm{C}$ and lowest was $-8 \sim-7^{\circ} \mathrm{C}$ (Korea Meteorological Administration, 2018a). At the end of March, ginger plants and early-blooming honeysuckles already had flowers around the forest, and alders and willows were also producing flowers. On the ground, beautiful corydalises were blooming in yellow flowers, while common Asian trigonotises and greater celandines were spreading their leaves.

\section{Plant therapy program}

The plant therapy program carried out (Wriggling Forest \& Wriggling Heart) was established with the guide of two Class 1 forest therapists, three forest interpreters, and one psychotherapist, moving in four groups. Each group took 2.5 hours, divided into four spaces as target areas.

Prior to experiencing the forest, the participants spent time appreciating the fact that they are alive by finding similarities between people and trees (human blood vessels and tree crown) and tapping on body parts such as heart, lungs and blood vessels to relieve tension and stretch. People take nourishment with food, and trees need solar energy to grow. Students moved a ball, which is considered solar energy, using their arms instead of hands to build affinity. The act of moving the ball with arms was done by holding hands with one another, which helped them relieve tension and relax their muscles.

In 'Forest Recalling the Past,' students found trees they liked and stared at them from the roots on the ground to the tip of the branches, looking at the curves of the trunks or traces of self-pruning and cut-off branches and recalling their pain from the past, thereby watching the trees' growth and comparing it to themselves. They also wrote down their current stress on pieces of paper or fallen leaves, and gathered them together and let go of their stress by hitting them with pine cones, floating the leaves containing their concerns onto the valley stream, or burying them underground.

In 'Forest Feeling the Present,' students learned that trees make their roots strong as they are shaken and thus only living trees are shaken, and that leaves undergo photosynthesis, transpiration and respiration. Trees need carbon dioxide and humans need oxygen, and thus they coexist by exchanging them. Students can feel this by sitting or lying down for a

Table 1. Forest distribution of Chungbuk National University Woraksan Research Forest

\begin{tabular}{|c|c|c|c|c|}
\hline No. & Variety & Diameter at breast height $(\mathrm{cm})$ & Age (year) & Crown density (\%) \\
\hline 1 & Pine & $>30$ & $51 \sim 60$ & $>71$ \\
\hline 2 & Other oaks & $18 \sim 30$ & $31 \sim 40$ & $>71$ \\
\hline 3 & Needle-broadleaf mixed forest & $18 \sim 30$ & $41 \sim 50$ & $>71$ \\
\hline
\end{tabular}

Table 2. Climate data of Chungbuk National University Woraksan Research Forest

\begin{tabular}{ccc}
\hline \multirow{2}{*}{ Climate information } & Average temperature for the year $\left({ }^{\circ} \mathrm{C}\right)$ & Average precipitation for the year $(\mathrm{mm})$ \\
\cline { 2 - 3 } & $11 \sim 12$ & $1200 \sim 1300$ \\
\hline Weather record & Highest temperature in March $\left({ }^{\circ} \mathrm{C}\right)$ & Lowest temperature in March $\left({ }^{\circ} \mathrm{C}\right)$ \\
\cline { 2 - 3 } & $19 \sim 20$ & $-8 \sim-7$ \\
\hline
\end{tabular}


while, focusing on breathing or feeling the silence.

In 'Forest Resolving the Future,' students watched the sprouts or willow blossoms that endure the bitter winter cold and come up from the ground or winter buds of trees through the loupe, or smelled ginger blossoms and branches to realize that growth requires time for waiting and pain, and humans must let go of some things to grow just like trees that let go of yesterday's leaves to make new ones. They also put hopeful messages to overcome their stress in bracelets, and resolved to think of their resolutions whenever they look at the bracelets. Finally, they shared one thing they liked in the forest and transferred the positive energy to the friend next to them, forming one big circle together. Then they shouted out their future resolution and wrapped up (Table 3).

\section{Measurement tools}

\section{School life stress}

Stress of college students can be measured by stress about life events mostly related to studies or stress about daily hassles. As a scale to measure stress, this study used 10 items related to school life stress from the 'Stress Factor Questionnaire' by Won and Kim (1985) and 'Stress Response Questionnaire for College Students' by Choi (1986), which are revised by Park (1991) without making any revisions (Wang, 2015).

Stress that may occur in school life of college students is internal and external mental stimulation related to studies, which reflects the uncomfortable mental state that may appear as tension, concern, depression or nervousness experienced based on pressure or strain caused by school studies or grades. This can be referred to as concerns about grades and exams, discrimination of professors, fear about class, and difficulties or concerns caused by the limit of abilities. This was rated on a 5-point Likert scale (1 point: strongly disagree -5 points: strongly agree) with total 10 items of the questionnaire used by Kim (2011) where the internal consistency reliability of the stress scale (Cronbach's alpha) was .78 (Table 4).

\section{Positive affect and negative affect}

Affect (or emotion) indicates mental health (Diener, 1984) and is classified into positive and negative affect. According to Lyubomirsky et al., (2005), positive affect has been studied actively in studies about it promoting individual health and its relationship with physical health and psychological well-being. Negative affect has been studied in terms of its relationship with problem behaviors such as psychopathology, suicide, violence and stress (Gwon and Sung, 2010). Affect can be defined as follows. First, affect can cause affective experiences such as pleasure, displeasure and arousal; second, it

Table 3. Contents of healing program

\begin{tabular}{lll}
\hline \multicolumn{1}{c}{ Subject } & \multicolumn{1}{c}{ Objective } & \multicolumn{1}{c}{ Detailed instruction } \\
\hline $\begin{array}{l}\text { Transfer your } \\
\text { energy }\end{array}$ & $\begin{array}{l}\text { Releasing stress in your body and } \\
\text { mind, relaxing muscles }\end{array}$ & - Being thankful for life by touching or tapping parts of your body \\
\hline $\begin{array}{l}\text { Forest Recalling } \\
\text { the Past }\end{array}$ & $\begin{array}{l}\text { Comparing personal growth to that of } \\
\text { a growing tree }\end{array}$ & $\begin{array}{l}\text { - Looking at the tree, identify stressors that tree had to overcome to grow } \\
\text { - Write down shared stressors that you and the tree have overcome on a leaf } \\
\text { and let the leaf float away }\end{array}$ \\
$\begin{array}{ll}\text { Forest Feeling the } \\
\text { Present }\end{array}$ & $\begin{array}{l}\text { Realizing all forms of life are } \\
\text { connected }\end{array}$ & $\begin{array}{l}\text { Concentrating on yourself with mindful breathing with trees } \\
\text { - Trees provide oxygen while humans provide carbon dioxide forming a } \\
\text { symbiotic relationship }\end{array}$ \\
$\begin{array}{l}\text { Forest Resolving } \\
\text { the Future }\end{array}$ & $\begin{array}{l}\text { Hoping for the future by observing } \\
\text { budding plants }\end{array}$ & $\begin{array}{l}\text { - Imagining the future as a bud that sprouts in the winter and flowers in the } \\
\text { spring }\end{array}$ \\
\hline
\end{tabular}


Table 4. Questionnaire measuring the stress in college students

\begin{tabular}{cl}
\hline No, & Question content \\
\hline 1 & I am worried that even if I study hard, my grades will not improve \\
2 & I am annoyed that there are too many test subjects \\
3 & I am having a hard time in university \\
4 & I am at the limit of my capability \\
5 & I am dissatisfied with the professor's discrimination \\
6 & My university atmosphere is too rigid \\
7 & I am annoyed by having to take tests too often \\
8 & I am afraid to go to class where teachers are overly critical \\
9 & I have too much to worry about besides studying at university \\
10 & I am worried about not knowing how to study effectively \\
\hline
\end{tabular}

Table 5. Terms for questionnaire in PANAS (Positive Affect and Negative Affect Schedule)

\begin{tabular}{lc}
\hline Positive Affect & Attentive, Active, Alert, Excited, Enthusiastic, Determined, Inspired, Proud, Interested, Strong \\
\hline Negative Affect & Hostile, Irritable, Ashamed, Guilty, Distressed, Upset, Scared, Afraid, Jittery, Nervous
\end{tabular}

can cause the cognitive process related to affect; third, it can cause physiological regulation; and fourth, it can cause expressive, goal-oriented and adaptive behaviors in some cases (Lim, 2017).

Affect regulation helps people understand and deal with their emotions by clearly perceiving them. Measurement of affect is classified into positive and negative affect as provided in the study by Shin (2008). Positive affect is defined as a psychological response felt by individuals as cognitive elements connected to joy, happiness and gratitude, and negative affect is defined as a psychological response felt by individuals as cognitive elements regarding anxiety, depression, sorrow and fear. The scales measuring positive and negative affect consist of total 20 items (10 items each) rated on a 5-point Likert scale (1 point: strongly disagree - 5 points: strongly agree) (Table 5). The Cronbach $\alpha$ coefficients for reliability and validity of research variables on school life stress and affect in the evaluation tool used in this study were 0.7 or higher, indicating that the items were measured at a stable level (Wang, 2015).

\section{Data processing method}

The data collected in this study were analyzed using the Excel 2010 statistical program. The general characteristics of the subjects were analyzed using descriptive statistics. A paired samples t-test was conducted to test the school life stress and positive effect of emotions before and after the forest healing program, with the significance level of $p<.05$ or lower.

\section{Results and Discussion}

\section{Results of analyzing the effects on school life stress}

Total 77 (49 male and 28 female) out of 82 copies of the questionnaire collected in this study were used in final data analysis excluding 5 copies with insincere responses, consisting of 29 first-year students (16 male and 13 female), 25 second-year students (18 male and 7 female), and 23 third-year students (15 male and 8 female).

As a result of conducting a t-test to determine whether forest healing plant therapy reduces school life stress of college 
students, the overall mean somewhat decreased from 2.42 to 2.30 (0.12), but the result was not significant ( $\mathrm{t}=1.90, p>.05)$. This is because in the preliminary survey on school life stress, an average of 25.7 (89\%) out of 29 first-year students, 21.2 (85\%) out of 25 second-year students, 17.9 (78\%) out of 23 third-year students, and 64.8 (84\%) out of all 77 students responded as strongly disagree (1 point), disagree ( 2 points), and neutral ( 3 points). It was discovered that school life in early March did not give much stress for first, second and third-year students in the in the Department of Forest Science at Chungbuk National University. However, there was a slight decrease after the program, which indicates that plant therapy helps reduce school life stress.

\section{Effects of plant therapy on positive affect of college students}

As a result of conducting a t-test to determine whether plant therapy increases positive affect of the participants, the result turned out to be significant ( $\mathrm{t}=-4.54, p<.001)$, increasing the overall mean from 3.05 to 3.24 (0.19 increase) after the program with statistical significance (Table 7).

\section{Effects of plant therapy on negative affect of college students}

The negative affect of the participants showed effects at a significant level $(\mathrm{t}=6.438, p<.001)$ as a result of the $\mathrm{t}$-test,

Table 6. College students' stress score of school life before and after forest therapy

\begin{tabular}{|c|c|c|c|c|c|c|}
\hline \multicolumn{2}{|c|}{ Grade } & M & SD & $\mathrm{t}$ & df & $p$ \\
\hline \multirow{2}{*}{ First year student } & Before & 2.35 & 0.69 & \multirow{2}{*}{0.56} & \multirow{2}{*}{28} & \multirow{2}{*}{.57} \\
\hline & After & 2.30 & 0.79 & & & \\
\hline \multirow{2}{*}{ Second year student } & Before & 2.30 & 0.64 & \multirow{2}{*}{0.68} & \multirow{2}{*}{24} & \multirow{2}{*}{.49} \\
\hline & After & 2.23 & 0.63 & & & \\
\hline \multirow{2}{*}{ Third year student } & Before & 2.63 & 0.53 & \multirow{2}{*}{1.85} & \multirow{2}{*}{22} & \multirow{2}{*}{.07} \\
\hline & After & 2.37 & 0.07 & & & \\
\hline \multirow{2}{*}{ Total } & Before & 2.42 & 0.65 & \multirow{2}{*}{1.90} & \multirow{2}{*}{76} & \multirow{2}{*}{.06} \\
\hline & After & 2.30 & 0.73 & & & \\
\hline
\end{tabular}

Note. 5 -point Likert scale questions were used (1= strongly disagree; $5=$ strongly agree).

${ }^{*} p<.05$

Table 7. The result of pre- and post-test about positive affect (PANAS scale) before and after forest therapy

\begin{tabular}{|c|c|c|c|c|c|c|}
\hline \multicolumn{2}{|c|}{ Grade } & M & SD & $\mathrm{t}$ & df & $p$ \\
\hline \multirow{2}{*}{ First year student } & Before & 3.08 & 0.40 & \multirow{2}{*}{-2.29} & \multirow{2}{*}{28} & \multirow{2}{*}{$.005^{*}$} \\
\hline & After & 3.22 & 0.38 & & & \\
\hline \multirow{2}{*}{ Second year student } & Before & 3.08 & 0.68 & \multirow{2}{*}{-2.78} & \multirow{2}{*}{24} & \multirow{2}{*}{$.002^{*}$} \\
\hline & After & 3.24 & 0.71 & & & \\
\hline \multirow{2}{*}{ Third year student } & Before & 2.97 & 0.43 & \multirow{2}{*}{-2.82} & \multirow{2}{*}{22} & \multirow{2}{*}{$.000^{* *}$} \\
\hline & After & 3.25 & 0.29 & & & \\
\hline \multirow{2}{*}{ Total } & Before & 3.05 & 0.52 & \multirow{2}{*}{-4.54} & \multirow{2}{*}{76} & \multirow{2}{*}{$.000^{* *}$} \\
\hline & After & 3.24 & 0.43 & & & \\
\hline
\end{tabular}

Note. 5-point Likert scale questions were used ( $1=$ strongly disagree; $5=$ strongly agree).

${ }^{*} p<.05, \stackrel{* *}{p} p<.001$ 
decreasing the overall mean from 2.40 to 2.12 ( 0.28 decrease) after the program with statistical significance. However, the mean of second-year students decreased but did not show significant change $(p<.05)$ (Table 8$)$.

\section{Effects of plant therapy on male and female college students}

In terms of changes in positive and negative affect of male and female participants, the change in the negative affect of female students also turned out to be significant $(p<.01)$. The mean of positive affect increased but with no significant change ( $p<.05)$. Male students showed a significant change $(p<.001)$ in both positive and negative affect. This indicates that they preferred physical activities and adventurous elements more than female students over cognitive activities in a stiff position indoors (Table 9).

The cause of change in positive and negative affect may be the attention restoration effect of the forest. According to the Attention Restoration Theory by Kaplan and Kaplan (1989), the natural environment may have restored the depleted attention restoration resources even without demanding intentional attention. According to the theory, the elements of restoration are fascination, being away, extent and compatibility. These elements refer to fascinating sounds or fragrances, being away and free from physical and mental activities that require close attention, so extensive as to create a new world, and has compatibility or consistency between desire and purpose of behavior (Kaplan, 1995). In particular, being away

Table 8. The result of pre- and post-test about negative affect (PANAS scale) before and after forest therapy

\begin{tabular}{|c|c|c|c|c|c|c|}
\hline \multicolumn{2}{|c|}{ Grade } & M & SD & $\mathrm{t}$ & df & $p$ \\
\hline \multirow{2}{*}{ First year student } & Before & 2.26 & 0.61 & \multirow{2}{*}{3.02} & \multirow{2}{*}{28} & \multirow{2}{*}{$.005^{*}$} \\
\hline & After & 2.11 & 0.62 & & & \\
\hline \multirow{2}{*}{ Second year student } & Before & 2.46 & 0.18 & \multirow{2}{*}{1.17} & \multirow{2}{*}{24} & \multirow{2}{*}{.26} \\
\hline & After & 2.32 & 0.58 & & & \\
\hline \multirow{2}{*}{ Third year student } & Before & 2.51 & 0.12 & \multirow{2}{*}{5.1} & \multirow{2}{*}{22} & \multirow{2}{*}{$.000^{* *}$} \\
\hline & After & 2.09 & 0.30 & & & \\
\hline \multirow{2}{*}{ Total } & Before & 2.40 & 0.57 & \multirow{2}{*}{2.4} & \multirow{2}{*}{76} & \multirow{2}{*}{$.000^{* *}$} \\
\hline & After & 2.12 & 0.69 & & & \\
\hline
\end{tabular}

Note. 5-point Likert scale questions were used (1= strongly disagree; $5=$ strongly agree).

${ }^{*} p<.05,{ }^{* *} p<.001$

Table 9. Comparison of male and female students before and after forest therapy

\begin{tabular}{|c|c|c|c|c|c|c|}
\hline Grade & & M & SD & $\mathrm{t}$ & $\mathrm{df}$ & $p$ \\
\hline \multirow{2}{*}{ Male-positive affect } & Before & 3.04 & 0.46 & \multirow{2}{*}{-4.56} & \multirow{2}{*}{48} & \multirow{2}{*}{$.000^{* *}$} \\
\hline & After & 3.27 & 0.38 & & & \\
\hline \multirow{2}{*}{ Male-negative affect } & Before & 2.39 & 0.62 & \multirow{2}{*}{6.23} & \multirow{2}{*}{48} & \multirow{2}{*}{$.000^{* *}$} \\
\hline & After & 2.03 & 0.64 & & & \\
\hline \multirow{2}{*}{ Female-positive affect } & Before & 3.06 & 0.58 & \multirow{2}{*}{-1.68} & \multirow{2}{*}{27} & \multirow{2}{*}{.104} \\
\hline & After & 3.19 & 0.53 & & & \\
\hline \multirow{2}{*}{ Female-negative affect } & Before & 2.42 & 0.52 & \multirow{2}{*}{2.51} & \multirow{2}{*}{27} & \multirow{2}{*}{$.018^{*}$} \\
\hline & After & 2.28 & 0.52 & & & \\
\hline
\end{tabular}

Note. 5 -point Likert scale questions were used (1= strongly disagree; $5=$ strongly agree).

${ }^{*} p<.05, \stackrel{* *}{p}<.001$ 
from school may have helped them become psychologically and emotionally stable without any other effort as they could blend into the beauty of Woraksan Mountain and reduce mental fatigue and academic stress.

Ulrich (1983) developed a theory emphasizing the reduction of stress through interaction between people and nature, which is the process characterized by emotions and feelings that are created by nature and bring positive physiological effect. Experiences in nature are related to spiritual health and growth, self-realization and psychological health. Thus, outdoor contact with nature is important (Erin, 2011). Considering the results above, plant therapy in the forest for college students turned out to be effective in increasing positive affect and decreasing negative affect, thereby consistent with the study that both direct and indirect experiences in the forest environment have positive effects on improving the mood (Jeon, 2017) and the study that merely being in a forest environment for a short time can relax the mind and body (Song et al., 2017).

\section{Conclusion}

This study was conducted to determine the pretest and posttest changes in the effects of plant therapy, one of the six major therapies of forest healing, on school life stress and affect of college students. To this end, the plant therapy program was carried out with the first, second and third-year students of Chungbuk National University at the Woraksan Mountain research forest affiliated with the university. The result showed that school life stress decreased from 2.42 to 2.30 on average $(p>.05)$ but did not show significance. Positive affect showed a significant increase in the overall mean from 3.05 to 3.24. Negative affect showed a significant decrease in the overall mean from 2.40 to 2.12 ( $p<.05)$. This indicated that plant therapy in the forest had a considerable influence on positive and negative affect of college students. As for gender differences, positive and negative affect of male students showed a significant $(p<.001)$ change, whereas for female students, the program was helpful in decreasing negative affect more than increasing positive affect.

Since the therapeutic effects of various environmental factors of the forest are caused by diverse and complicated interactions, it is difficult to regard them merely as a mechanism.

The results of this study are expected to be used in developing and implementing various programs for college students to more actively make a habit of activities in the forest, thereby coping with stress and emotions in school or daily life. The limitations of the results are as follows.

First, since the study was conducted on first, second and third-year students of the Department of Forest Science, there are limitations in generalizing and applying the results to students in other departments or all college students, and thus continued research must be conducted on all college students.

Second, college students may have different factors of stress depending on their college year. Accordingly, there must be comparative research according to year and department.

Third, only short-term effects were verified using only a part of the outdoor learning time. There is a need for long-term follow-up research, as well as research on the persistence of the effects after the program.

\section{References}

Choi, H.R. 1986. Stress of korean university students and cognitive-behavioral counseling. Doctoral dissertation, Ewha Womans University, Seoul, Korea.

Choi, W.K. 2013. The structural relationship among college students' life stress, maladaptive cognitive emotion regulation, frustrated interpersonal needs and suicidal ideation. Doctoral dissertation, Kyungpook National University, Daegu, Korea. 
Diener, E. 1984. Subjective well-being. Psychol. Bull. 95(3):542-575. DOI:10.1037/0033-2909.95.3.542

Erin, L.W. 2011. Cultivating healthy places and communities: evidenced-based nature contact recommendations. Int. J. Environ. Health Res. 21(1):41-61. DOI:10.1080/09603123.2010.499452

Gwon, G.N. and M.Y. Sung. 2010. The influences of young children`s happiness on behavior problems and interpersonal problem solving strategies. Korean J. Human Ecol. 19(2):257-270.

Hwang, C.H. 2012. Analysis of stress for a college students. J. Korean Aging Health Friendly Policy Assoc. 4(1):73-82.

Jeon, J.Y. 2017. The effects of direct and indirect forest experience on human psychology and physiology. Master's thesis, Chungbuk National University, Cheongju, Korea.

Kaplan, R. and S. Kaplan. 1989. The Experience of Nature: A Psychological Perspective. New York, USA: Cambridge University Press.

Kaplan, S. 1995. The restorative benefits of nature: Toward an integrative framework. J. Environ Psychol. 15(3):169-182. DOI:10.1016/0272-4944(95)90001-2

Kim, K.W., Y.H. Lee, H.Y. Kim, C.Y. Kim, J.W. Kim, and R.H. Yu. 2008. Healing forest operations program initiative of San-Um. Proceedings of spring conference of Korean Institute of Forest Recreation (pp. 41-44). Daejeon, Korea.

Kim, M.J., J.W. Lee, K.W. Kim, R.H. Yu, Y.H. Choi, and B.J. Park. 2011. An application of major facilities for forest therapy. Proceedings of spring conference of Korean Institute of Forest Recreation (pp. 65-68). Gyeongju, Korea.

Kim, N.Y. 2011. A study on the relationship between college student stress, social support, and college life satisfaction. Master's thesis, Konkuk University, Gwangju, Korea.

Korea Forest Service. 2011. Forest Healing Instructor Level 1 Book. Daejeon, Korea: Author.

Korea Forestry Promotion Institute (KOFPI). 2018. Forest information inquiry system 'Dadream'. Retrieved from https://www.kofpi.or.kr/service/imupInfo_01.do

Korea Meteorological Administration (KMA). 2018a. Highest and lowest temperature of March. Retrieved from http://www.weather.go.kr/weather/climate/past_cal.jsp

Korea Meteorological Administration (KMA). 2018b. Average of 30 years. Retrieved from http://www.weather.go.kr/ weather/climate/average_30years.jsp

Kusuhara, M., K, Urakami, Y. Masuda, V. Zangiacomi, H. Ishii, S. Tai, K. Maruyama, and K. Yamaguchi. 2012. Fragrant environment with $\alpha$-pinene decreases tumor growth in mice. Biomed. Res. 33(1):57-61. DOI:10.2220/biomedres. 33.57

Lee, S.S. 2015. Effects of forest therapy program in school forest on employment stress and anxiety of university students. Master's thesis, Chungbuk National University, Cheongju, Korea.

Li, Q. and T. Kawada. 2013. Effect of forest environments on human immune function. In Q. Li (Ed.), Forest medicine (pp. 67-86). Hauppauge, NY: Nova Science Publishers, Inc.

Lim, S.S. 2017. Validation of korean well-being scales for university students: Flourishing and positive and negative experience. Master's thesis, Kyungpook National University, Daegu, Korea.

Lyubomirsky, S., L. King, and E. Diener. 2005. The benefits of frequent positive effect: Does happiness lead to success? Psychol. Bull. 131(6):803-855. DOI:10.1037/0033-2909.131.6.803

Oh, K.H., D.J. Kim, J.G. Kim, and Y.S. Kim. 2016. The effects of forest-healing program on developing youth activity competence. Korean J. Youth Stud. 23(2):1-24

Park, S.H. 1991. A study on stress, depression, and psychological health of female high school students. Master's thesis, Inha University, Inchon, Korea.

Selye, H. 1982. History and present status of the stress concept. In L. Goldberger and S. Breznitz (Eds.), Handbook of Stress: Theoretical and Clinical Aspects. New York, NY: Free Press.

Shin, A.Y. 2008. Effects of emotion-mindfulness on emotional clarity, cognitive regulation of emotion, physical symptoms, and well-being for female college students. Master's thesis, Duksung Women's Universty, Seoul, Korea.

Shin, J.Y. 2014. The mediating effects of ego-resilience and coping strategy, social support in the relation between life stress and on adjustment in college life. Doctoral dissertation, Daegu Catholic University, Daegu, Korea. 
Song, C., H. Ikei, M. Kobayashi, T. Miura, Q. Li, T. Kagawa, S. Kumeda, M. Imai, and Y. Miyazaki. 2017. Effects of viewing forest landscape on middle-aged hypertensive men. Urban For. Urban Green. 21:247-252. DOI:10.1016/j.ufug.2016.12.010

Ulrich, R.S. 1983. Aesthetic and affective response to natural environment. In I. Altman, J.F. Wohlwill (Eds), Behavior and the Natural Environment. Human Behavior and Environment (Advances in Theory and Research), Vol 6. Boston, MA: Springer.

Wang, W. 2015. The effect of concentration on stress and emotional response. Master's thesis, Kongju National University, Gongju, Korea.

Won, H.T. and S.H. Kim. 1985. A study of stress factors in college students. Stud. Res. by Center for Campus Life \& Culture, Seoul National University. 20(1):43-51.

Yu, L.H. 2007. A case study on the application of forest healing. A study on Forest Science by Korea Forest Service. 70:45-60. 